\title{
Review
}

\section{Acupuncture Anesthesia and Analgesia for Clinical Acute Pain in Japan}

\section{Reina Taguchi}

\author{
Department of Clinical Acupuncture and Moxibustion II Meiji University of Oriental Medicine, Kyoto, Japan
}

\begin{abstract}
Acupuncture anesthesia has been practiced in China since about 1960. In Japan, Hyodo reported 30 cases of acupuncture anesthesia in 1972. However, from around 1980, the direction of acupuncture investigations turned from anesthesia to analgesia. Acupuncture analgesia is presently considered a way to activate the body's endogenous analgesic system. Recently, with the rise of acupuncture as one of the most well known CAM therapies, acupuncture or moxibustion treatment has been reported for both acute and chronic pain. Even so, few clinical reports and original articles have been reported in Japan. This review illustrates how acupuncture is being used in Japan for acute pain such as surgical operations, post- operative pain (POP), neuropathic pain, pain associated with teeth extractions and after the extraction of impacted wisdom teeth.
\end{abstract}

Keywords: acupuncture analgesia - acupuncture anesthesia - acute pain - individual variation neuropathic pain - pain after extraction of impacted wisdom teeth - pain from teeth extractions - post-operative pain - surgery operation

\section{Introduction}

In 1971, a Japanese newspaper article on acupuncture anesthesia in China reported that low frequency electrical acupuncture (LFEA) was being used for anesthesia in abdominal operations such as appendicitis and that the consciousness of the patients remained clear during the operations. This report accelerated fundamental study on acupuncture anesthesia and analgesia and acupuncture treatment was used for analgesia in the treatment of pain in Japan. The first examination of acupuncture anesthesia was done in China in about 1960. In Japan, Masayoshi Hyodo pioneered 30 cases of acupuncture anesthesia in 1972 at Osaka Medical College and became one of the more experienced persons using acupuncture anesthesia (1). Acupuncture anesthesia has some benefits: (i) it is simple and easy without complicated tools, (ii) there are no side effects, (iii) non-painful areas are induced without

For reprints and all correspondence: Reina Taguchi, Department of Clinical Acupuncture and Moxibustion II Meiji University of Oriental Medicine Hiyoshi-cho, Nantan-city, Kyoto 629-0392, Japan.

Tel: (+81)771-72-1181 (extension 538); E-mail: r_sekido@meiji-u.ac.jp the involvement of innervations of the areas stimulated by acupuncture, (iv) the anesthetic effects last after acupuncture anesthesia and (v) the wound heals more quickly.

There are some drawbacks, however: (i) anesthesia produced by acupuncture has individual variations and (ii) too much time is needed to induce anesthesia. For these reasons, investigations of acupuncture analgesia in preference to acupuncture anesthesia accelerated in the latter half of the 1980s. Numerous animal and clinical experiments carried out in various parts of the world led to wide recognition of acupuncture as a viable modality for the relief of pain (2-5). Acupuncture analgesia is presently considered a way to activate the body's endogenous analgesic system (6) (Fig. 1A). Recently, it was reported that the acupuncture analgesia in inflammation condition differs from that in normal condition and immunosystem is involved in acupuncture analgesia on inflammation condition $(7,8)$ (Fig. 1B).

In Japan, the analgesic benefits of acupuncture and moxibustion treatment for various kinds of pain are also accepted experimentally. However, this use has led

(C) 2007 The Author(s).

This is an Open Access article distributed under the terms of the Creative Commons Attribution Non-Commercial License (http://creativecommons.org/ licenses/by-nc/2.0/uk/) which permits unrestricted non-commercial use, distribution, and reproduction in any medium, provided the original work is properly cited. 
A

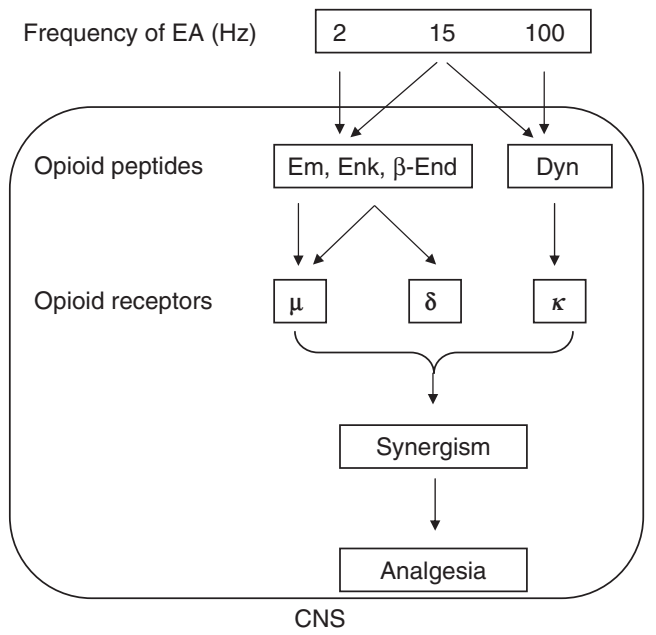

B

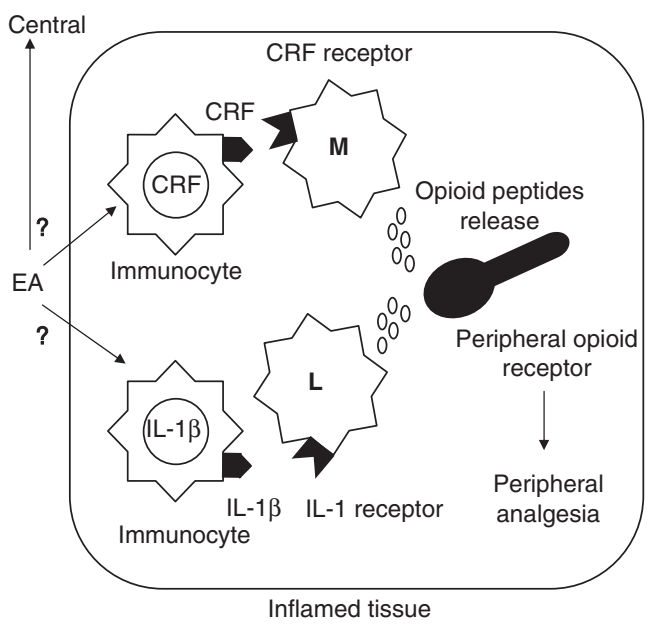

Figure 1. Possible mechanism for acupuncture analgesic and anesthesia. (A) Normal condition. Opioid peptides and receptors involved in analgesia elicited by EA of different frequencies. Activation of all three types of opioid receptors produces a synergistic analgesic effect. Abbreviations: Em; endomorphin. Enk; enkephalins, $\beta$-End; $\beta$-endorphin, Dyn; dynorphin. (B) Inflammation condition. EA might be able to release CRF and IL-1 $\beta$ from immunocytes within inflamed tissue. CRF or IL-1 $\beta$ elicited by EA may trigger the release of opioid peptides within inflamed tissue which may make peripheral opioid receptors active, reducing neuronal excitability or release of pro-inflammatory neuropeptides (e.g. substance P), thereby inhibiting pain. EA, electoacupuncture; CRF, corticotropin releasing hormone; IL-1 $\beta$, interleukin $1 \beta$; M, macrophage; L, lymphocyte.

to very few clinical reports and original articles. With this review, I intend to introduce fundamental research into acupuncture analgesia and the clinical research on acupuncture analgesia and anesthesia for acute pain that have been conducted in Japan.

\section{Methods}

A database search published in Japan, using 'Igaku Chuo Zasshi (between 1982 and 2006)' and Medline were performed. Articles published before 1982 were extracted from the reference data of other articles. Proceedings were removed and reports in which the methods of treatment and results were shown clearly became the target of my search.

\section{Results}

\section{Acupuncture Analgesia for Healthy Volunteers}

\section{Acupuncture and Transcutaneous Electrical Nerve Stimulation (TENS) Raises the Pain Threshold}

Numerous studies have shown that acupuncture, ear acupuncture, silver spike point (SSP) and TENS increase the somatic pain threshold (1,9-15). Kitade and Hyodo (9) examined the influence of ear acupuncture point stimulation on the somatic pain threshold. Among the ear points, the lungs, sympathicus, Shen-Men and kidneys exhibited a remarkable increase in the pain threshold in comparison to a non-acupuncture ear point.
Although the results varied considerably according to the individual and region of the body, to some extent they clarified that ear acupuncture points had counterparts in certain body regions and the authors were able to conclude that ear acupuncture was useful in achieving analgesia or anesthesia. Ishimaru and co-workers also examined how LFEA and SSP influenced the pain threshold in the abdominal area (10). Both LFEA and SSP induced analgesic effects in the abdominal area and acupuncture analgesia produced by LFEA was faster and higher than that of the SSP stimulation. These results suggested that LFEA and SSP would be beneficial for the control of pain after abdominal surgery. Katayama et al. further investigated the effect of acupuncture analgesia on gingival tissue by using the 'Hoko' points. When 'Deqi' was not obtained by needling, the alleviation of pain was not improved. However, when 'Deqi' spread out from elbow to shoulder, there was noticeable improvement in the alleviation of pain. Moreover, they revealed that a better analgesic effect was obtained by a $30 \mathrm{~min}$ treatment rather than one only lasting $15 \mathrm{~min}$ (11).

As for deep pain threshold, a few reports investigated the influence of LFEA and TENS on the deep pain threshold of the skin surface as well as in the area $3 \mathrm{~mm}$ below the skin, the fascia, the muscle and the periosteum $(12,13)$. The greatest increase in deep pain threshold occurred when cutaneous stimulation using a noninsulated needle was combined with deep stimulation using an insulated needle. It was also clarified that the pain threshold of these tissues varied according to the electrodes used; the area stimulated by electrical 
acupuncture (insulated or non-insulated needle) and TENS (SSP, rubber and jeltrode). Thus, LFEA, SSP and TENS could increase the somatic and deep pain threshold. Since the increase in pain threshold varies according to electrode and stimulated area, it is important to use the electrode most suitable to the purpose.

\section{Endogenous Opioid Peptides May Be Involved During Acupuncture Analgesia}

Other authors investigated the mechanisms underlying the increased pain threshold produced by LFEA, SSP and TENS. Kitade and associates found that although the pain threshold increased by LFEA for 50 min, LFEA did not increase the plasma $\beta$-endorphin and adrenocorticotropic hormone $(\mathrm{ACTH})$ in the cerebral spinal fluid (CSF) (14). These results suggested that $\beta$-endorphin in plasma and CSF were not involved during acupuncture analgesia. It was considered, however, that there were some kinds of endogenous opioid peptides involved in acupuncture analgesia, because acupuncture analgesia was antagonized by naloxone, an opioid receptor antagonist. Similarly, Ishimaru and co-workers showed that LFEA for $30 \mathrm{~min}$ produced acupuncture analgesia (15). They found, however, that although plasma $\beta$-endorphin increased after the LFEA $(15,16)$, plasma ACTH did not change (16). This result was in line with findings of patients with post-operative pain (POP) (16). These results suggested that although plasma $\beta$-endorphin induced by LFEA was involved in acupuncture analgesia, other analgesic mechanisms that differ from stressinduced analgesia might also be involved.

\section{Acupuncture Analgesia Varies in Healthy Volunteers}

Kitade and associates examined the enhancing effect of D-phenylalanine (DPA) on acupuncture analgesia in healthy volunteers (17). DPA is thought to suppress the activity of carboxypeptidase, which decomposes endorphins. They were administered $4.0 \mathrm{~g}$ DPA orally $30 \mathrm{~min}$ before the application of acupuncture. The results showed that acupuncture analgesia appeared gradually after LFEA was started and gradually disappeared after termination of LFEA. DPA, however, remarkably enhanced the analgesic effects of LFEA in all cases when it was administered orally before acupuncture treatment. It was concluded that DPA was able to enhance the effects on acupuncture analgesia in humans. Hyodo et al. (18) studied whether DPA influenced acupuncture analgesia or not, using 15 healthy volunteers and proved that DPA significantly prolonged the rise in pain threshold of all five subjects whose pain threshold was raised after LFEA (respondents). Out of 10 subjects whose pain threshold remained almost unchanged after LFEA (non-respondents), the pain threshold was increased by DPA in five cases.
Kitade and co-workers examined the inhibitory effect of naloxone on the enhanced acupuncture analgesia by pre-administration of DPA (19). It was found that all four respondents whose rise in pain threshold persisted after DPA+LFEA, experienced a drop in PT after intravenous injections of naloxone. These results suggest that DPA enhances the analgesic effect of acupuncture by the 'endorphin mechanism'.

\section{Acupuncture Anesthesia and Analgesia for Acute Pain}

\section{Acupuncture Anesthesia for Surgical Pain}

In Japan, by the middle of 1972, Hyodo had experimented with 30 cases of acupuncture anesthesia one elbow operation, three clavicular operations, three sinus operations, two tonsillectomies, four teeth extractions, three oral tumor resections, four evacuations of the uterus, two transvaginal hysterectomies, two vaginal polyp operations, one Madrener's operation, one Schulocker's operation, one Schauter's operation, one rectovaginal fistule operation and one neck tumor operation (1). He performed the largest acupuncture anesthesia first. Although it may not be rational to summarize the success rate for such a variety of operations, $80 \%$ of the operations were successful. Acupuncture anesthesia was also performed by Kudoh and co-workers on 11 patients requiring minor surgical operations [tumor enucleation (subdorsal, brow, breast, abdomen, cervical, crus) onychectomy, ganglion extraction] (20). At first the patients were given $4 \mathrm{~g}$ DPA and then they received LFEA to LI-4 and ST-36, with simultaneous high frequency electrical acupuncture to the operative field. The results showed that the pain threshold significantly increased after commencing LFEA and the operations of five in 11 patients were carried out solely by acupuncture anesthesia. They also concluded that LFEA increased the pain threshold of skin satisfactorily, but not enough for surgery in deep tissues.

\section{Acupuncture Analgesia for Postoperative Pain (POP) After Abdominal and Chest Surgery}

There are many reports that investigated the use of acupuncture, SSP and TENS for POP after abdominal and chest surgery $(16,21-26,29,30)$ and a large number showed efficacy. Wu and co-workers revealed that SSP modified POP after abdominal surgery and prompted a recovery of the reduced vital capacity of post-surgical patients in the early post-operative period (21). Kishida et al. (22) also showed that improvement in lung vital capacity coincided with the relief of POP after TENS procedure. Moreover, it was found that SSP with a mixed stimulation of local high frequency stimulation and remote low frequency stimulation offered the most relief 
from POP $(23,24)$. Thus, many reports showed that acupuncture, SSP and TENS were effective for the relief of POP and reduced the dose of analgesic drugs but without clarifying the mechanisms underlying the relief of POP. As to the mechanisms, Ishimaru et al. $(16,25,26)$ first reported that plasma $\beta$-endorphin concentration increased during acupuncture and SSP stimulation, and concluded that $\beta$-endorphin levels induced by acupuncture and SSP stimulation reduced the POP. They coincidentally investigated ACTH levels during acupuncture. It is generally considered that $\beta$-endorphin and ACTH are simultaneously released from the pituitary during stress-induced analgesia and that their levels increase plasma during acupuncture $(27,28)$ and it is considered that acupuncture produced stress-induced analgesia. However, Ishimaru et al. $(16,26)$ found that plasma $\beta$-endorphin concentration increased during acupuncture, while ACTH did not. These results differed from Malizia's and Masala's results in plasma ACTH concentration.

Thus, acupuncture may not produce stress-induced analgesia and the increased plasma $\beta$-endorphin may be involved in some other mechanisms. Suzuki et al. (29) also reported that acupuncture was effective in POP that was resistant to analgesic drugs showing that the skin temperature of painful areas was low and elevated when POP was relieved after acupuncture. They considered that the sympathetic nerves of the skin were excited by surgical stress and POP, inducing vasoconstriction and decreasing the blood flow in the skin, which in turn lowered the skin temperature of painful areas. Accordingly, they suggested that acupuncture relieved POP by modifying the excitability of the sympathetic nerves and rise in skin temperature, giving another possible mechanism in addition to the activation of the endogenous analgesic system.

\section{Acupuncture Analgesia on Pain during Teeth Extractions and After Extraction of Impacted Wisdom Teeth}

Kamei et al. (31) extracted teeth under acupuncture analgesia using DPA pre-medication. Forty patients were divided into two groups: a test group (nine cases) that had DPA administration $30 \mathrm{~min}$ prior to acupuncture analgesia and group (31 cases) that had only acupuncture analgesia. In the acupuncture analgesia group, absolutely no pain or only slight pain was felt in about $30 \%$ of the cases while in the test group there was almost no need for supplementary local anesthesia and generally good results were obtained in most cases. Kitade et al. (32) also investigated the efficacy of acupuncture analgesia in teeth extractions using DPA premedication on 56 patients in a double-blind placebo-controlled study. The study showed that the efficacy of acupuncture analgesia in teeth extractions increased to $35 \%$ by DPA pre-administration compared with 38 placebo group cases. They also concluded that DPA pre-administration enhanced acupuncture analgesia for teeth extractions. Katayama et al.(33) evaluated acupuncture analgesia in multiple teeth extractions on 131 cases (1614 teeth) which needed dentures. LFEA were carried out on the following acupuncture points; Hego, Sanjian, Renzhong, Yingxiang, Sibai, Quanliao, Xiaguan, Daying, Jiache, Dicang and Chengiiang. The results showed that although 56 cases $(43 \%)$ attained complete analgesia and partial but tolerable analgesia was achieved in 50 cases $(38 \%), 25$ cases $(19 \%)$ required local anesthesia due to severe pain. In addition, less blood was lost with the use of acupuncture.

SSP and LFEA have also been investigated for pain relief after impacted wisdom tooth extraction $(34,35)$. There was a significantly longer period of relief from pain using a combination of LFEA and local anesthesia in patients with difficult extractions that required gingival incision, showing that LFEA and SSP were viable not only for the pain of tooth extractions but also for pain after impacted wisdom tooth extraction.

\section{Acupuncture Analgesia on Acute Post-herpetic Neuralgia (PHN) and Neuropathic Pain (Mainly PHN and Reflex Sympathetic Dystrophy: RSD}

Acupuncture is likely to protect against acute PHN (at the time of a rash) $(36,37)$ and it has been reported that combined therapy using antiviral agents and early acupuncture promoted crust formation, with no trace of PHN (36). This result corresponds with that of Egawa et al. (37) who showed that combined therapy using antiviral agents and early acupuncture was more effective than therapy using only antiviral agents on early PHN, and that this combined therapy could suppress PHN.

Numerous clinical reports have also investigated the efficacy of acupuncture and LFEA for PHN (38-46). Tanabe and associates found that acupuncture was useful for PHN and more specifically, that acupuncture was more helpful for patients during the first two months after PHN induction (38). Similarly Arai (39) and Ishimaru (40) showed that acupuncture was effective for PHN that the first one month after its induction. Kawachi et al. (41) also reported that blood flow of the affected area was improved by both acupuncture and near infrared ray radiation, with an additional analgesic benefit.

Some articles showed that acupuncture treatment was valuable for RSD. Shoulder-hand syndrome (SHS) is involved in RSD or complex regional pain syndrome (CRPS) Type I and many of these cases are caused by trauma. Some cases, however, result from circulatory diseases such as cerebrovascular accidents and cardiac infarction and herpes zoster. The results of acupuncture on acute and chronic SHS after cerebrovascular accidents were described in three reports (47-49). Ding et al. (47) performed $20 \mathrm{~min}$ of manual acupuncture on 14 patients 
with post-hemiplegic SHS on the hemiplegic arm and hand, twice a week for 5 weeks. Local thermographic and laser doppler confirmed an increase in skin temperature and blood flow. The increases, however, were inhibited when $10 \mathrm{mg} \alpha$-blocker phentolamine was injected before the acupuncture treatment. Finally, after 5 weeks of acupuncture treatment, positive improvement was recorded in pain, local heating and swelling. These results suggest that acupuncture plays a therapeutic role through the suppression of increased sympathetic tone and corresponds with findings of other reports. Tsuiki et al. $(48,49)$ also showed that pain, swelling, skin temperature, paresthesia and Gibbon's RSD score improved after acupuncture treatment and concluded that acupuncture treatment was helpful for SHS that accompanied hemiplegia after a cerebrovascular accident and that the improvement of the peripheral blood flow might play an important role in generating treatment results. Thus, it seems that acupuncture increases peripheral blood flow to areas with decreased blood flow of the skin, while decreasing raised local heat.

\section{Conclusion}

In Japan, acupuncture treatment is valuable for acute pain such as surgical operations, post-operative pain (POP), neuropathic pain, pain from tooth extractions and extraction of impacted wisdom teeth. However, these areas are not exhaustive, because of the lack of clinical reports and original articles reported in Japan. A detailed examination should be done in the future to clarify treatment, dose, timing of treatment for acute pain and the propriety of acupuncture treatment.

\section{References}

1. Hyodo M, Nakamura N, Yukimati T, Ohki J, Yoshida A, Inamori $\mathrm{K}$, et al. The experience of acupuncture anesthesia. Masui. Jap J Anesthesiol 1973;22:251-8. (in Japanese)

2. Han JS, Xie GX. Dynorphin: Important mediator for electroacupuncture analgesia in the spinal cord of the rabbit. Pain 1984;18:367-76.

3. Chen XH, Geller EB, Adler MW. Electrical stimulation at traditional acupuncture sites in peripherary produces brain opioidreceptor-mediated antinociception in rats. J Pharmacol Exp Ther 1996;277:654-60.

4. Ma SX. Neurobiology of acupuncture: Toward CAM. Evid based Complement Alternat Med 2004;1:41-7.

5. Tsukayama H, Yamashita H. Systematic review of clinical trials on acupucnture in the Japanese literature. Clin Acupunct Orient Med 2002;3:105-13.

6. Han JS. Acupuncture: neuropeptide release produced by electrical stimulation of different frequencies. TRENDS in Neurosciences 2003;26:17-22.

7. Sekido R, Ishimaru K, Sakita M. Differences of electroacupunctureinduced analgesic effect in normal and inflammatory conditions in rats. Am J Chin Med 2003;31:955-65.

8. Sekido R, Ishimaru K, Sakita M. Corticotropin-releasing factor and interleukin-1 $\beta$ are involved in the electroacupuncture-induced analgesic effect on inflammatory pain elicited by carrageenan. Am J Chin Med 2004:32:269-79.

9. Kitade T, Hyodo M. The effects of stimulation of ear acupuncture points on the body's pain threshold. Am J Chin Med 1979;7:241-52.
10. Ishimaru K, Shinohara S, Kitade T, Morioka T, Kudou D, Umeki $\mathrm{N}$, et al. Effect on pain threshold of low frequency electrical acupuncture (LFEA) and silver spike point (SSP) electrical stimulation. Meiji Shinkyu Igaku. Bull Meiji Univ Orient Med 1990;6:61-7. (in Japanese)

11. Katayama I, Suzuki Y, Katayama T, Kochi T, Tsuzimoto Y, Matsumoto T, et al. Effect of the acupuncture anesthesia to gingival tissue by using the "Hoku" points. Bull Josai Dent Univ 1977;6:219-23. (in Japanese)

12. Ishimaru K, Shinohara S, Iwa M, Kawakita K, Higuchi J, Watanabe S, et al. Effects of electrical acupuncture on deep pain threshold in human subjects. Meiji Shinkyu Igaku. Bull Meiji Univ Orient Med 1991;8:27-33. (in Japanese)

13. Ishimaru K, Kawakita K, Sakita M. Analgesic effects induced by TENS and electroacupuncture with different types of stimulating electrodes on deep tissues in human subjects. Pain 1995;63:181-7.

14. Kitade T, Minamikawa M, Hyodo M, Nakao K, Oki S, Imura H. $\beta$-endorphin and ACTH concentrations in plasma and cerebrospinal fluid during acupuncture analgesia in human subjects. Touyouigaku to Peinkulinikku. Oriental Medicine and the Pain Clinic 1980;10:116-20. (in Japanese)

15. Ishimaru K, Sekido R, Sakita M. Association between endogenous analgesia and meridians in LI4 (Hegu, Gokoku) point electroacupuncture. Zen Nippon Shinkyu Gakkai Zasshi. J Jap Soc Acupunct Moxibust 2003;53:184-9. (in Japanese)

16. Ishimaru K. Effects of acupuncture analgesia on post-operative pain after abdominal surgery and the relationship of endogenous analgesic substances. Meiji Shinkyu Igaku. Bull Meiji Univ Orient Med 2000;26:11-22. (in Japanese)

17. Kitade T, Minamikawa M, Nawata S, Shinohara S, Hyodo M, Hosoya E. An experimental study on the enhancing effects of phenylalanine on acupuncture analgesia. Am J Chin Med 1981;9:243-8.

18. Hyodo M, Kitade T, Hosoya E. Study on the enhanced analgesic effect induced by phenylalanine during acupuncture analgesia in humans. Adv in Pain Res Ther 1983;5:577-82.

19. Kitade T, Odahara Y, Shinohara S, Ikeuchi T, Sakai T. Studies on the enhanced effect of acupuncture analgesia and acupuncture anesthesia by D-phenylalanine (first report)-effect on pain threshold and inhibition by naloxone. Acu Ele Ther Res Int J 1988;13:87-97.

20. Kudoh D, Kouda H, Watanabe K, Iwa M, Ishimaru K, Shinohara S, et al. Effects of electro-acupuncture stimulation on minor surgical operation. Meiji Shinkyu Igaku. Bull Meiji Univ Orient Med 1990;6:77-82. (in Japanese)

21. Wu CH, Kousa H, Yamakawa M, Shinohara S, Tawa M, Kitade T, et al. Effect of SSP (silver spike point) therapy on pain following abdominal surgery. J Kyoto Pref Univ Med 1989;98:437-44. (in Japanese)

22. Kishida H, Sakai E, Kanbara H, Ohno M, Hyodo M. A study on post operative analgesic effect of TENS, evaluated particularly with lung vital capacity and leg ability. Masui. The Japanese journal of Anesthesiology 1987:36:1160-5. (in Japanese)

23. Ishimaru K, Shinohara S, Kitade T, Kouda H, Kudou D, Watanabe $\mathrm{K}$, et al. Experimental study to increase analgesic effects for pain following abdominal surgerys by silver spike point therapy. Meiji Shinkyu Igaku. Bull Meiji Univ Orient Med 1989;5:1-6. (Japanese)

24. Umeki N, Iwa M, Ishimaru K, Shinohara S, Kitade T, Hata K, et al. Solver spike point therapy on the pain of post abdominal surgery. Meiji Shinkyu Igaku. Bull Meiji Univ Orient Med 1990;7:55-60. (in Japanese)

25. Miyakawa M, Ishimaru K, Ikeda $\mathrm{K}$, Osada $\mathrm{T}$, Imai $\mathrm{K}$, Iwa $\mathrm{M}$, et al. Effects of silver spike point electrical stimulation on pain after abdominal surgery. Meiji Shinkyu Igaku. Bull Meiji Univ Orient Med 1995;17:15-9. (in Japanese)

26. Ishimaru K, Imai K, Iwa M, Yoshioka Y, Sakita M. Effects of acupuncture analgesia on post-operative pain after abdominal surgery using serum $\beta$-endorphin and ACTH concentrations as parameters. J Jap Soc pain clin 1999;6:10-6. (in Japanese)

27. Malizia E, Andreucci G, Paolucci D, Crescenzi F, Fabbri A, Fraioli F. Electroacupuncture and peripheral $\beta$-endorphin and ACTH release levels. Lancet 1979;2:535-6.

28. Masala A, Santa G, Alagna S, Zolo TA, Rovasio PP, Rassu S. Suppression of electroacupuncture (EA)-induced $\beta$-endorphin and 
ACTH release by hydrocortisone in man. Absence of effects on EA-induced anaesthesia. Acta Endocrinol 1983;103:469-72.

29. Suzuki M, Egawa M, Yano T. Haigan setujyogo ni syoji, chintuyaku ni teikou wo simesita jyutugotoutuu no syourei. Post operative pain which showed resistance in medicine after lung cancer excision-A case report-. IDO-NO-NIPPON. J Jap Acupunct Moxibusit 2002;698:29-34. (in Japanese)

30. Kurokawa M. Jyutugotoutuu ni taisuru SSP ryouhou no chintuukouka nituite. Touyouigaku to Peinkulinikku. Orient Med Pain Clinic 1979;9:21-4. (in Japanese)

31. Kamei J, Kitade T, Toyota S, Kawachi A, Hyodo M, Nakano Y, et al. Acupuncture anesthesia with D- phenylalanine pre-med for tooth extractions. Zen Nippon Shinkyu Gakkai Zasshi. J Jap Soc Acupunct Moxibust 1981;31:136-9. (in Japanese)

32. Kitade T, Odahara Y, Shinohara S, Ikeuchi T, Sakai T. Studies on the enhanced effect of acupuncture analgesia and acupuncture anesthesia by D-phenylalanine (2nd report) schedule of administration and clinical effects in low back pain and tooth extraction. Acu Ele Ther Res Int J 1990;15:121-35.

33. Katayama I, Kochi T, Katayama T, Motoyoshi Y, Oonishi S, Sakazume K, et al. Clinical evaluation of acupuncture anesthesia in multiple extractions - A report on 131 cases - Bull Josai Dent Univ 1978;7:113-9. (in Japanese)

34. Kitade T, Ohyabu H. Analgesic effects of silver spike point (SSP) therapy on pain after mandibular wisdom tooth extraction. Touyouigaku to Peinkulinikku. Orient Med Pain Clin 1998;28:23-8. (in Japanese)

35. Kitade T, Ohyabu H. Analgesic effects of acupuncture on pain after mandibular wisdom tooth extraction. Nippon Sika Toyo Igaku Zasshi. J Jap Dent Soc Orient 1999;18:0-4. (in Japanese)

36. Ohno M. Effect of acupuncture in facial pain from herpes zoster. Shinkyuu Osaka. Osaka J Clin Acupunct Moxibust 1999;15:162-3. (in Japanese)

37. Egawa M, Ishizaki N, Hiro M, Yamada N, Yano T, Kakimura A, et al. The clinical evaluation of acupuncture therapy for herpes zoster-combined therapy using acyclovir and acupuncture-. Meiji Shinkyu Igaku. Bull Meiji Univ Orient Med 1991;9:23-31. (in Japanese)

38. Tanabe T, Shiba K. Taijyouhousin ni taisuru haritiryou no kouka. The effect of acupuncture for Herpes zoster. Zen Nippon Shinkyu Gakkai Zasshi. J Jap Soc Acupunct Moxibust 1984;33:383-7. (in Japanese)

39. Arai C. Herupesugosinkeitu ni taisuru haritiryou. Acupuncture treatment for PHN. IDO-NO-NIPPON. J Jape Acupunct Moxibust 2006;759:9-34. (in Japanese)
40. Ishimaru K. Herupesugosinkeitu no haritiryou. Acupuncture treatment for PHN. IDO-NO-NIPPON. J Jap Acupunct Moxibusit 2006;759:35-8. (in Japanese)

41. Kawachi A, Ichiji K. Taijyouhousingosinkeituu ni taisuru cyokusen henkou kinnsekigaisen syousya to haritiryou heiyou no ichirinsyoukeiken. A case report on combination of near infrared ray radiation and acupuncture treatment for PHN. IDO-NO-NIPPON. J Jap Acupunct Moxibust 2003;715:58-65. (in Japanese)

42. Araki M. Taijyouhousin ni taisuru teisyuuhachisinryouhou. The effect of low frequency electrical acupuncture for Herpes zoster. IDO-NO-NIPPON. J Jap Acupunct Moxibust 1985;494:22-7. (in Japanese)

43. Matsumoto T. Syoureihoukoku (23), Taijyouhousin. Herpes zoster. IDO-NO-NIPPON. J Jap Acupunct Moxibust 1987;519:11-4. (in Japanese)

44. Matsumoto T. Syoureihoukoku (28), Taijyouhousingosinkeituu. Postherpetic neuralgia. IDO-NO-NIPPON. $J$ Jap Acupunct Moxibust 1988;526:14-6. (in Japanese)

45. Fukuda F, Yano T. Taijyouhousingosinkeituu ni kouhindo harituudenryouhou ga koukateki de atuuta ichisyourei. [The effect of high frequency electrical acupuncture for Postherpetic neuralgia-A case report-] IDO-NO-NIPPON. J Jap Acupunct Moxibust 2003;719:42-5. (in Japanese)

46. Shinohara S, Shinohara M, Matsumoto T, Kitade T, Ishimaru K, Yukimati T. Acupuncture treatment of herpes zoster on intercostal neuralgia. Meiji Shinkyu Igaku. Bull Meiji Univ Orient Med 1987;3:71-7. (in Japanese)

47. Ding S, Kamitsuchihashi H, Shimodouzono M, Hiyoshi T, Tanaka N. The effects and mechanism of acupuncture on posthemiplegic shoulder- hand syndrome. Nippon Onsen Kikoh Butsuri Igakkai Zasshi. The Japanese Society of Balneology, Climatology and Physical Medicine 1993;56:95-102.

48. Tsuiki M, Yasuno F, Yokokawa K, Aikawa Y, Fukuda F, Sakai T. Acupuncture therapy for shoulder-hand syndromes (SHS). Zen Nippon Shinkyu Gakkai Zasshi. J Jap Acupunct Moxibust 2002;52:435-41. (in Japanese)

49. Tsuiki M, Yoshida A, Yasuno F, Aikawa Y, Fukuda F, Sakai T. The effects of acupuncture on shoulder-hand syndromes (SHS) as a complication of hemiplegia. Nippon Onsen Kikoh Butsuri Igakkai Zasshi. Jape Socy Balneol, Climatol Physical Med 2002;65:128-36. (in Japanese)

Received June 21, 2006; accepted March 22, 2007 


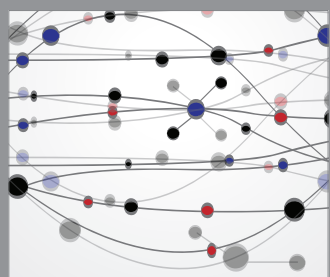

The Scientific World Journal
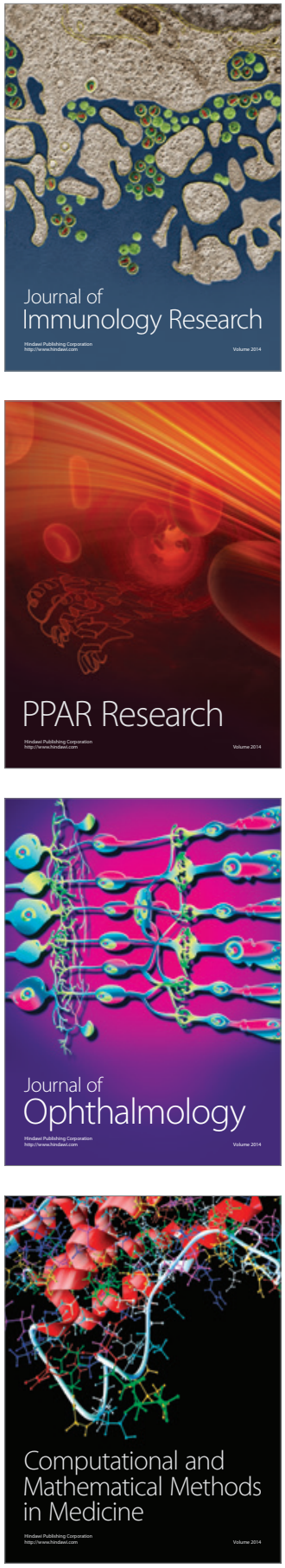

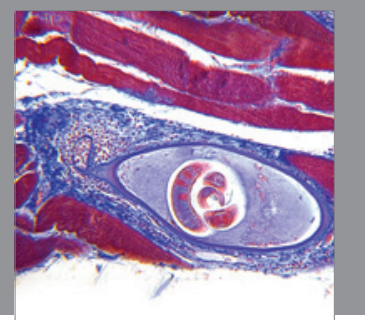

Gastroenterology

Research and Practice
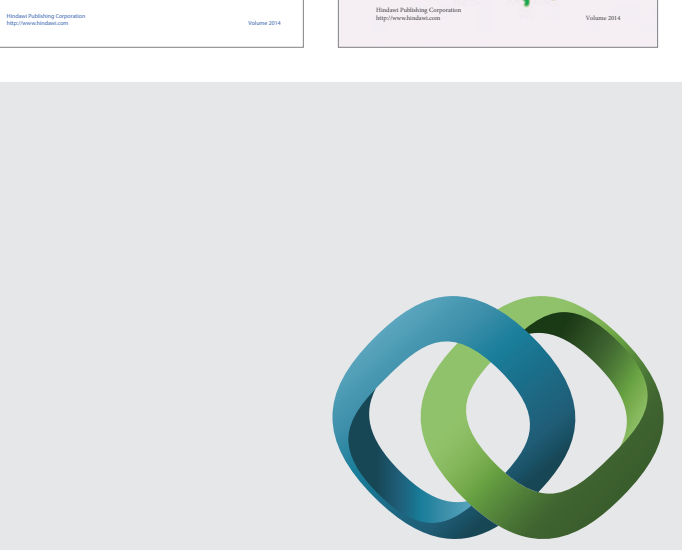

\section{Hindawi}

Submit your manuscripts at

http://www.hindawi.com
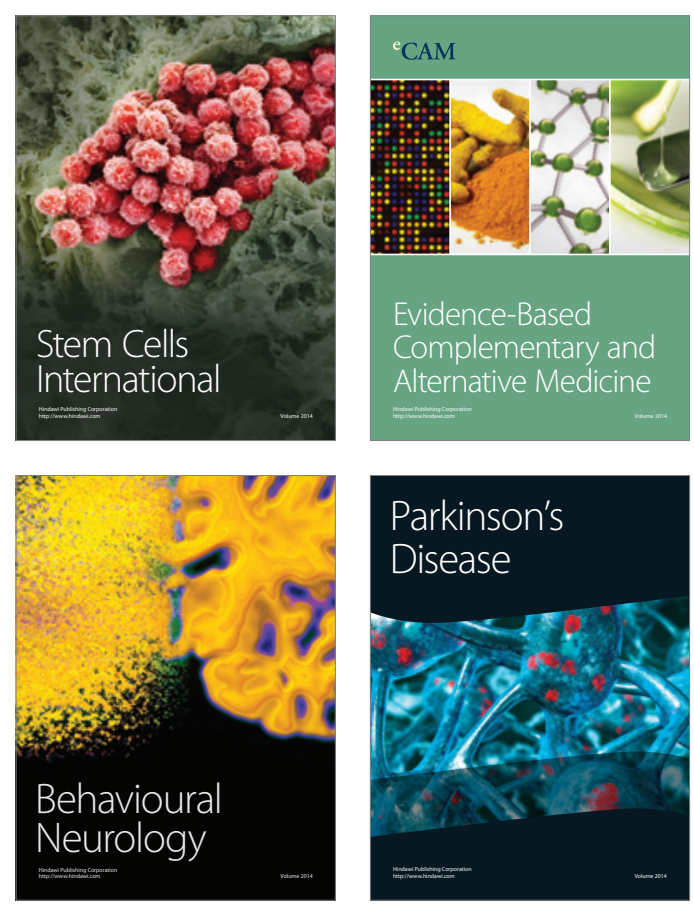

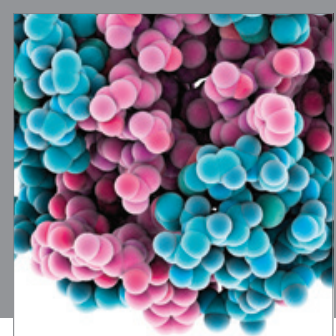

Journal of
Diabetes Research

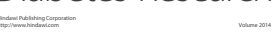

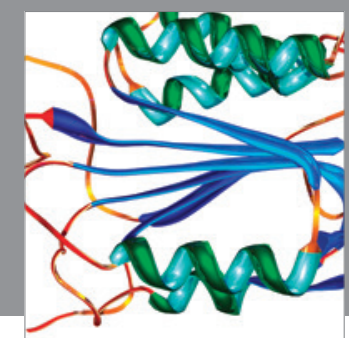

Disease Markers
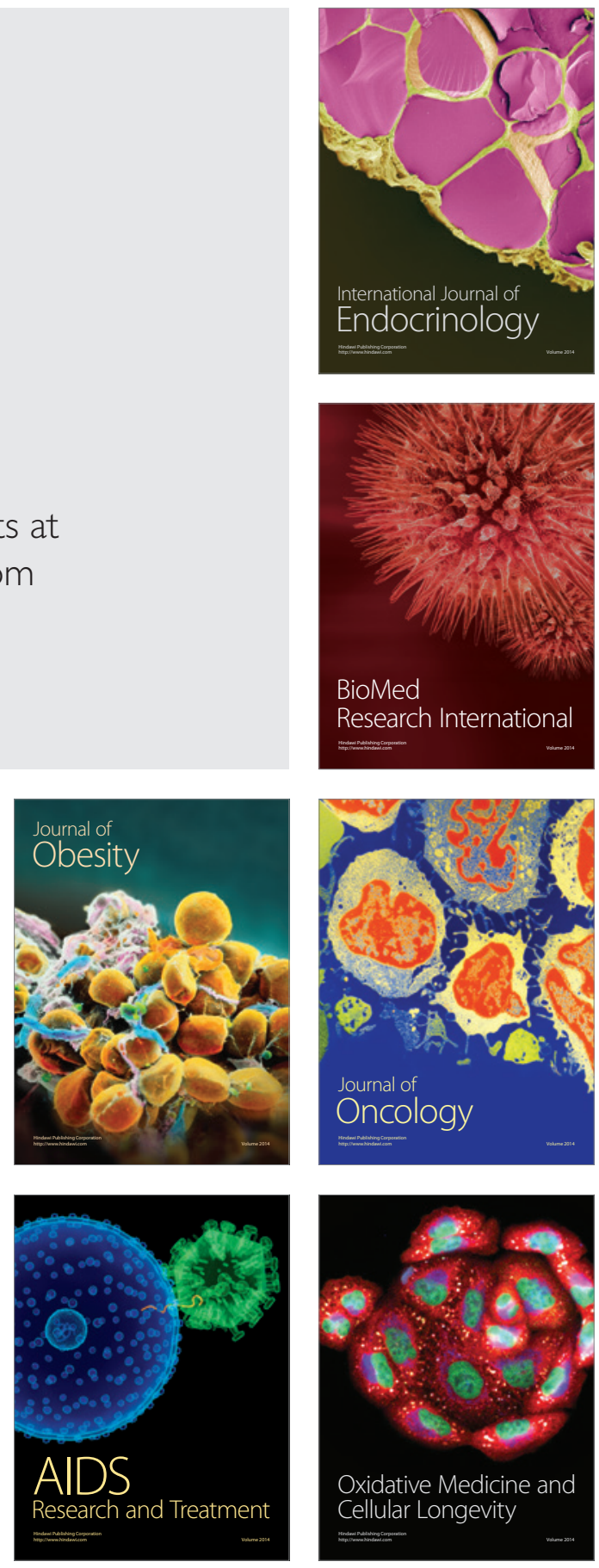